\title{
Exploration on the reform of operations research curriculum applied to economic management majors
}

\author{
Jie SU \\ School of Management Science and Engineering \\ Central University of Finance and Economics \\ Beijing, P.R.China \\ sujie@cufe.edu.cn \\ JunLin CHEN \\ School of Management Science and Engineering \\ Central University of Finance and Economics \\ Beijing, P.R.China \\ chenjunlin_cufe@163.com
}

\author{
ChuanLiang JIA \\ School of Management Science and Engineering \\ Central University of Finance and Economics \\ Beijing, P.R.China \\ cnbjjcl@163.com \\ HuiJia LI \\ School of Management Science and Engineering \\ Central University of Finance and Economics \\ Beijing, P.R.China \\ lihuu2000@126.com
}

\begin{abstract}
With the high-level requirement for quantitative analysis in the economic management field, the importance of operations research curriculum for undergraduate students of Economic management major is significantly emerging. How to combine operations research that is strong theoretical and highlevel quantization requiring with the economic management cultivation that requires strong application, in order to allow students to learn and master this course better, is the core issue on the reform of operations research curriculum applied to economic management major. In this paper, we analyze issues that economic management major will confront when using traditional teaching methods of operations research, combined with specific reality, and propose corresponding teaching reform program of operations research courses for students of economic management major.
\end{abstract}

keywords-operations research; economic management major; undergraduate stage; teaching reform

\section{INTRODUCTION}

Operations research is an emerging discipline that starts from the 1930s. Its main object is to provide managers with the scientific basis for decision-making, which is one of the important approaches to achieve effective management, good decisions and modernized management. Recently, with the transition of management from emphasizing the qualitative decision to emphasizing quantitative decision, many theoretical approaches of operations research have become a powerful tool for modernized management. In terms of economic analysis, production management and investment decisions, they have a very wide range of applications. Operations research has also become one of the important basic courses in economic management major in colleges. As a branch of applied mathematics, operations research requires students to have a quite solid mathematical theory foundation, thus it is used to be

This work was supported by the Professional Promotion Plan of Central University of Finance and Economics. set in courses of science and engineering major, with emphasis on exploring theory. If this discipline is promoted in traditional teaching way in the economy and management major in which students are taught more applications and relatively have unsubstantial mathematical basis, so that it will emphasize teaching mathematical theory and contempt cultivation of students' abilities to solve practical problems. However, it is far from meeting the development demands of economic management talents and also will lead to diverse teaching problems. Therefore, reform of teaching methods of operations research in economic management major needs to be done urgently; many scholars have also done research in this area. For example, F.L. Wei and etc. constructed the theory and practice interaction teaching system of operations research course in economic and management major based on the analysis of characteristics and problems in the teaching of operations research course[1]. To improve the application abilities of students, Z.B. Fane and etc. gave some new suggestions on the teaching reformation of operations research curriculum[2]. M.S.Yang proposed the pattern and mentality of educational reform and exploration of operation research promoted by scientific research[3].

In this paper, we analyze the issues that economic management major confronts because of traditional teaching mode of operations research, seeing through the surface to essence of the problems, combined with the actual situation of the economic management major, for the purpose of improving students' ability to apply operations research to solve practical problems, and we propose some teaching reform proposals for economic management major. 
II. PROBLEMS BETWEEN THE TRADITIONAL OPERATIONAL RESEARCH CURRICULUM AND THE UNDERGRADUATE TRAINING OF ECONOMIC MANAGEMENT MAJOR

\section{A. Curriculum base is not adapted to the characteristics of economic management major}

According to the history of operations research development in China, operations research belonged to mathematics discipline over a long period of time. This makes the traditional operations research teaching excessively emphasize research on mathematical theory, with high mathematical foundation requirements, which require students to master mathematical analysis, advanced algebra and other courses. However, mathematics foundation of the students in the economic management major with strong nature of the liberal arts is weak. Therefore, traditional operations research education will lead to inadaptation of curriculum basis to the features of the economic management major.

\section{B. Focus on theoretical lectures and contempt cultivation of students' proficiency}

Since operations research rises from mathematics in China, it results in excessive emphasis on explanations of mathematical theory and theorem derivation in the traditional operations research teaching process. Some teachers even are caught in construction complex mathematical models and exploration of clever manual solution, while ignore the cultivation of students' abilities to solve practical problems. For economic management major students, it is very difficult to learn and also discourage them from studying operations research initiatively.

\section{Inappropriate Teaching content}

Operations Research contains a number of branches, with rich contents, and has a very wide range of applications in industrial engineering, mechanical optimization, computer science, economic management and other aspects. Traditional operations research is mainly offered in science and engineering major, and traditional teaching materials whose involved content or practical examples are biased to science and engineering is no longer appropriate for economic management major.

\section{Teaching and assessment methods are too single}

Traditional teaching method is the "write on the blackboard with chalk". For students of economic management major, such an "infusion type" of teaching methods is too boring and it can not raise e students' interest in this course, which leads to a decline in teaching efficiency.

In addition, the traditional way of teaching assessment is too simple. It generally is the end of closed-book exam to assess teaching effectiveness, but it is difficult to test the students' ability to solve practical problems.

\section{EXPLORATION ON THE TEACHING MODE OF OPERATIONS RESEARCH APPLIED TO ECONOMIC MANAGEMENT MAJOR}

What can be seen through the above analysis is that, along with development of economic and social, applications of operations research in the field of economic management are more widely and operations research has become one of important basic courses of economic management major. However, if we still teach operations research to students of economics management major in accordance with the traditional teaching methods, it will result in serious problems. After years of teaching exploration, combined with characteristics of the economic management majors regarding applications, we suggest that teaching mode of operations research in economic management should make the following improvements:

\section{A. Attention to the cultivation of method of thinking}

Operations research is applied mathematics, belonging to quantitative management courses, with highly logic. Its formulas, theorems and basic concepts are easy to forget as time goes on after students grasp them. But after students comprehending its ways of thinking, they will never forget and benefit from it in the future learning and work, when these ways of thinking help them draw inferences.

\section{B. Teaching theory as well as focus on the cultivation of students' application ability}

For economic management major, teaching operational research should not only focus on teaching boring theory, while improving students' application ability to solve practical problems is the main purpose. So the traditional way of teaching should be done the following improvements:

1) Increasing the case teaching method

The aim of case teaching is to enable students to explore knowledge instead of just acquiring knowledge, which is an initial attempt. First of all, we should select operations research cases that suit to students of economic management major. Second, we should not be too care about cases is right or wrong to let students have more self-play space. Finally, students should be encouraged to complete the case with mutual discussions, and such way can make thinking active as well as stimulate the interest of students.

2) Increasing the Experimental Teaching

Lindo, Lingo, Excel and other software should be introduced into this course to improve students' ability on the basis of mastering the basic theory, allowing them to apply their knowledge to complete case analysis process by using software After the completion of the boring theory study, students can get the fun from using software to solve operations research problems. In addition, the majors which have good conditions should set up such course "management science models and application" to improve students' ability to operate. As a follow-up course of operations research, this course is to further enhance the students' ability of operation

3) The practice teaching is essential

In the form of classroom practice, we lead students into the operations research practice laboratory, where teachers and 
students complete practical teaching activities together by understanding the purpose of the experiment and the experimental requirements, and really operating by students themselves. Ion the other hand, we can guide some students into the enterprises to understand the actual business operation. Then we guide them to make the use of operations research knowledge to model and come up with the optimal management plan, with continuous feedback in practice.

\section{Greater efforts to improve the teaching content}

Many domestic colleges and universities has realized this problem which is that the traditional teaching content of operations research are not the right for students of economic management major, and they has launched a number of improvements, including writing or translating high level textbooks which meet the new demands, enrich teaching links and reform the teaching content. For instance, Tsinghua University publishes a series of famous American textbooks, like "Introduction to Operations Research", "Operations Research: Decision Making Method", and this action plays a good role in promoting for reform of domestic operations research textbook. In addition, the textbook "operational research" that written by teacher Jie $\mathrm{Su}$ and etc. is also used by many domestic economic management colleges and universities. Thus, during the process of teaching, we should choose textbooks that suit to our own students. The schools which have good conditions should organize teams to write corresponding teaching materials, and such teaching contents will be more fit students' reality.

\section{Rich teaching and assessment methods}

\section{1) Strengthen the construction of network quality curriculum \\ Building high-quality courses can make teaching team seriously rich teaching resources. We can also upload all the teaching resources on the Internet to share with everyone, and actively listen to feedback, and ultimately improve teaching methods. Each teacher can also take full advantage of online course platform to put courseware, syllabus, exercises and other information on the Internet, and interacts with students on the platform to answer questions and discuss.}

\section{2) Rich final assessment methods}

The only assessment method, the end of a closed-book exam, is too boring, and it is difficult to test the students' ability to solve practical problems. So assessment methods should be to diversify.

First, case analysis assessment method mentioned above can be adopted; Furthermore, the routine assessment should focus on feedback, so that we can deeply understand that students grasp how much knowledge, and mutually inform to examine teaching vulnerabilities and improve teaching level. During the class, to encourage students to speak and communicate, we should give certain usual awards to students who have a good classroom performance appraisal. Finally, in extra-curricular teaching activities, we should actively organize and encourage students to participate in Mathematical Modeling Contest to improve their abilities to integrate theory with practice, which can also be used as a way of final assessment.

\section{E. Rich teaching and assessment methods}

Building teaching teams rather than emphasis on individual teachers teaching ability in traditional teaching ways will help to improve teaching methods.

First, in the process of teaching team building, we should focus on interdisciplinary cross. Teachers can come from different colleges, and theoretical research as well as applied research should be all included. This may effect mutual promotion very well through mutual exchanges and integration

At the same time, team of teachers should be mainly young and middle-aged teachers, but should include a certain number of old professors: young and middle-aged teachers are in the prime of life with active thinking and they have a more profound professional knowledge, bringing vitality to the team; teaching experience of old professors can't be ignored, because they can provide effective guidance to teaching methods for young teachers.

\section{CONCLUSION}

In this paper, we first analyze the importance of operations research in the field of economic management, asserting that this course should be given due attention in economic management majors; then we analyze issues that economic management major will confront when using traditional teaching methods of operations research which is emphasis on teaching the theory; Finally, we see through the appearance to perceive the essence and put forward corresponding educational reform programs, such as the formation of the teaching teams and teaching content improvement. This will bring some help to the reform of teaching methods of operations research in economic management majors, but the thorough teaching reform mode still requires further exploration.

\section{REFERENCES}

[1] F.L. Wei, and C.M. Hu. "Discussion on Theory and Practice Interaction Teaching System of Operations Research Course in Economic and Management Major." Research \& Exploration in Laboratory(2011).

[2] Z.B.Fan, Z.Q. Tang, "Deepening teaching reformation of operations research and improving application abilities of students", [J]. Journal of Fuyang Teachers College, 2010.

[3] M.S. Yang,F.L. Kong, W.Zhang, "The Educational Reform and Exploration of Operation Research Promoted by Scientific Research", [J]. Journal of Xian University of Architecture \& Technology, 2006.

[4] Z.M.Li, J.H. Zhu, D.S. Qiu, et al. "Practices in Heuristic Method of Teaching for the Course of Operational Research", [J]. Journal of Higher Education Research, 2008.

[5] D.J. Wang, "The Teaching of Operations Research and Mathematical Modelling", [J]. College Mathematies, 2003. 